\title{
STAT-IMM, a statistical approach to determine local and background contributions to $\mathrm{PM}_{10}$ levels
}

\author{
W. Enke, F. Kreienkamp, and A. Spekat \\ Climate \& Environment Consulting Potsdam GmbH, Potsdam, Germany \\ Received: 10 January 2008 - Revised: 4 March 2008 - Accepted: 4 June 2008 - Published: 3 July 2008
}

\begin{abstract}
When studying concentrations of particulate matter with a size of $10 \mu \mathrm{m}$ or below $\left(\mathrm{PM}_{10}\right)$, measured locally, it becomes evident that two main portions need to be quantified: The concentration produced by sources in the vicinity of the station and the long range transports. The traditional approaches include analyses of the components of $\mathrm{PM}_{10}$, comparisons upwind and downwind of a station, investigation of trajectories and complex chemical transport modelling. The development of an independent strategy which makes use of statistical methods, including regression and correlation analysis is a reasonable alternative. This method, presented here, does not apply the concept of $\mathrm{PM}_{10}$ sources, but, rather, analyzes the relations between times series of $\mathrm{PM}_{10}$ measurements and atmospheric properties. It is applied to identify the shares of the local portion and the large-scale background plus a stochastic portion that cannot be attributed to either of the two. Using regression analysis, a set of objectively chosen meteorological parameters is used to reconstruct the local $\mathrm{PM}_{10}$ measurement series, defining the local portion. This weather-dependent part of the series is then removed and the residuum, which contains the large-scale $\mathrm{PM}_{10}$ background and a stochastic portion is analyzed further with correlations. Results are shown for a three-year set of data which includes well over $250 \mathrm{PM}_{10}$ stations across Germany. The data is analyzed according to different stratifications, such as the $\mathrm{PM}_{10}$ load and the wind direction as well as for the data set as a whole. In a further development of the method, a study of $\mathrm{PM}_{10}$ transports across several border sections is shown.
\end{abstract}

\section{Introduction}

\subsection{Demands on an assessment of $\mathrm{PM}_{10}$ portions}

The pollution load of particulate matter, both from local emissions and longe range transports, constitutes a major problem in air quality. Meteorological conditions determine how the particles are transported and which concentrations are detected locally. In order to assess the effort/benefit ratio of regional and federal emission reduction measures in Germany, the share of measured concentrations of particulate matter of $10 \mu \mathrm{m}$ or less $\left(\mathrm{PM}_{10}\right)$, advected from outside the country, is of major importance (EU, 1996; EU-Council, 1997; EU, 1999; Garber et al., 2002). Therefore, a major goal is to discern the average $\mathrm{PM}_{10}$ portions local $\left(\mathrm{I}_{\mathrm{L}}\right)$, large-scale background $\left(\mathrm{I}_{\mathrm{B}}\right)$ and stochastic $\left(\mathrm{I}_{\mathrm{S}}\right)$.

In the past there were numerous studies which aimed at the identification of local and background portions of pollutants,

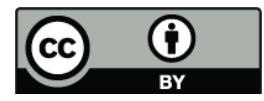

Correspondence to: A. Spekat (arne.spekat@cec-potsdam.de) which often used a combination of physical and statistical methods, e.g., Merrill et al. (1985), Harris and Kahl (1990) or Oltmans et al. (1996). Studies, e.g., by Man and Shih (2001), van Dingenen et al. (2004), Querol et al. (2004) or Querol et al. (2007) were focusing on particulate matter. This study aims to complement them and offers a straightforward approach to discern the $\mathrm{PM}_{10}$ portions.

Such an exercise should keep representativity in mind. Thus it should be able to produce results for a continuous time span and describe average conditions. It should furthermore aim at a description that can be verified by actual measurements. We are aware that $\mathrm{PM}_{10}$ observations contain gaps and errors. A detailed investigation of these factors is given in Warnecke et al. (2006). Rigorous state-of-theart quality control including homogenization and correction must be performed beforehand. It is acknowledged that after the application of these procedures there may be remanent systematic errors in the $\mathrm{PM}_{10}$ levels but experience shows that the variability of the measurement errors is considerably lower. The method presented here focuses on regression and correlation which both evaluate variabilities rather than means. 
All causes for potential errors notwithstanding, we argue that the use of $\mathrm{PM}_{10}$ measurements is more effective than the determination of source strengths, because for the latter the processes that produce and convert $\mathrm{PM}_{10}$ are not sufficiently known, wherefore a source-based $\mathrm{PM}_{10}$ quantification has considerable error margins (Stern, 2006).

\subsection{Approaches to $\mathrm{PM}_{10}$ assessment}

There are four main approaches to quantify what is produced in the vicinity and what is belonging to the background, possibly transported over longer distances.

- Laboratory analysis of $\mathrm{PM}_{10}$ components (Stohl and Kromp-Kolb, 1994; Lenschow et al., 2001; Querol et al., 2004): This method is better suitable for $\mathrm{PM}_{10}$ episodes than for an assessment of the mean state.

- Upwind/Downwind Method (Hainisch and Neubauer, 2004): Here, groups of measurements upwind and downwind of potential $\mathrm{PM}_{10}$ sources are compared. This method has expedient aspects because it uses concentrations (that which is received at a measurement station), rather than emissions, i.e., source strengths which are very difficult to estimate (cf. Sect. 1.1).

- Trajectory analysis (Danielsen, 1974; Seibert, 1993): This method combines elements of the sourceidentifying laboratory analyses and the quantitative upwind/downwind approach by way of tracing the origin of $\mathrm{PM}_{10}$ concentrations measured at a station. It is better suitable for single high-concentration episodes than for the assessment of an extended time span.

- Transport modelling (Yamartino et al., 1992; Stern, 2003, 2006): This set of approaches aims at a physically appropriate description of all $\mathrm{PM}_{10}$-relevant processes. This very complex approach is highly dependent on a correct assumption of the magnitude of the $\mathrm{PM}_{10}$ sources - prone to large uncertainties (cf. Sect. 1.1). As noted in van Loon et al. (2004) and Stern (2006), this is particularly visible in these models' underestimation of measured high $\mathrm{PM}_{10}$ concentrations.

It should be added that, for all approaches above, terms like "local", "background", "vicinity" or "long distance" are used by the respective authors as orientation categories rather than being attributable to fixed sizes. A definition according to the statistical method presented here is given in Sect. 3.3.

\subsection{STAT-IMM, yet another method?}

At first, a distinction of the German pollution terminology should be pointed out. It forms the word pair emissionimmission in order to tell apart quantities that are produced and those which are arriving at a point of reference. Since "immission" is not part of the international terminology, we have resorted to the term "concentration" for the text. However, this emission-immission concept was also used for naming the $\mathrm{PM}_{10}$ analysis method in German, hence it is called STAT-IMM, i.e., STATistical analysis of IMMission measurements. The method is based on a few key theses which link physical properties and mathematical/statistical concepts:

1. The variability (a second order moment) of a $\mathrm{PM}_{10}$ series can, after minimizing the local $\mathrm{PM}_{10}$ contribution, be separated into long-range transport and stochastical portion.

2. The terms large-scale background and long-range transport can be used in an equivalent way.

3. The correlation coefficient, when applied as in item 1 is the measure of the variability's (percentual) fraction of the large-scale background;

4. The magnitude of the large-scale background can be linked to and expressed by the standard deviation of the series.

STAT-IMM evaluates solely concentrations, thus circumventing the problematic assessment of source strengths. It applies the statistical techniques of regression and correlation to a spatial set of $\mathrm{PM}_{10}$ measurements. By themselves, these techniques are of course not novel but STAT-IMM applies them in a different setting, comprehensively described in Kreienkamp et al. (2007). They are employed to indirectly reconstruct local time series - a necessary step in assessing the local $\mathrm{PM}_{10}$ component (by way of regression), to assess the magnitude of the long range transport (by way of correlation) and to separate long-range transport from stochastic fluctuations (also by way of correlation). Another important STAT-IMM feature is that it is not restricted to selected episodes - it addresses a continuous timeframe, for summer and winter separately.

\section{Data}

The following data types were used:

- Atmospheric three-dimensional climatology data from the NCEP-NCAR Reanalyses (Kalnay et al., 1996). Atmospheric data are supplying the predictors for the regression analysis and they are used for large-scale wind direction information.

- Air quality data from the data archive of the German Federal Environment Agency (UBA). 268 stations measuring $\mathrm{PM}_{10}$ from 2001 to 2003 were used; half-hourly data were aggregated into hourly data, from which daily averages were computed. Data quality control and the supplement of missing data were carried out by the fully automated tool sYSTWARN (Kreienkamp and Enke, 2005). 
- Air quality data from the AIRBASE/AIRVIEW web archive of the European Environment Agency (EEA), European Topic Center (ETC) for Air and Climate Change. 344 station time series from the Czech Republic, Austria, Switzerland, France and the Netherlands for the 20012003 period were selected. Quality control and the supplement of missing data were performed as with the German subset.

\section{Method}

\subsection{Analysis of spurious correlations}

Within STAT-IMM, spurious associations, such as annual and weekly cycles are identified and removed. The former is of no relevance to the results, since a large-scale, continuous data set is analyzed in which annual cycles are heterogeneous without phase consistency whilst the latter is subject to human-induced fluctuations (e.g. traffic or industry). The portion that can be attributed to the weekly cycle amounts to $3 \%$ of the total signal at most. This is a rather low figure due to the long, continuous time span analyzed, the high variability of weekly cycles and the effect that long range $\mathrm{PM}_{10}$ transports may interfere with the weekly cycle.

\subsection{Determination of the local portion of $\mathrm{PM}_{10}$}

The local portion $\left(\mathrm{I}_{\mathrm{L}}\right)$ is identified first and then removed. To achieve this, a regression analysis is employed. Local time series of $\mathrm{PM}_{10}$ are indirectly reconstructed by way of other properties, called predictors. The practise of determining relations between large scale atmospheric information and local measurements is well established, e.g., in the perfect prog approach (Klein, 1971; Kruizinga and Murphy, 1989) in statistical weather forecasting as well as in downscaling techniques for large-scale climate models (Enke and Spekat, 1997). The full set of potential predictors which is offered to the screening regression procedure would contain some 30 atmospheric parameters. This set, however, needs to be reduced, a step that is a necessary to achieve a regression based on local characteristics of the atmosphere. There are properties, such as the advection, which are by definition non-local and therefore have to be excluded from the set of predictors. We are aware that this is a compromise, because in principle all properties have a potential to improve the quality of the regression. However, the non-local predictors would be adding elements of ambiguity to the regression equation and thereby also diminish the efficiency of the procedure used to determine the large-scale background. In practise, out of the reduced pool of potential predictors the regression process objectively chooses the ones with the highest predictive power in a stepwise screening approach. Up to four of the potential predictors are allowed to be chosen for each station; a higher number would increase the danger of overfitting and numerical instability. The predictors which the screening re-

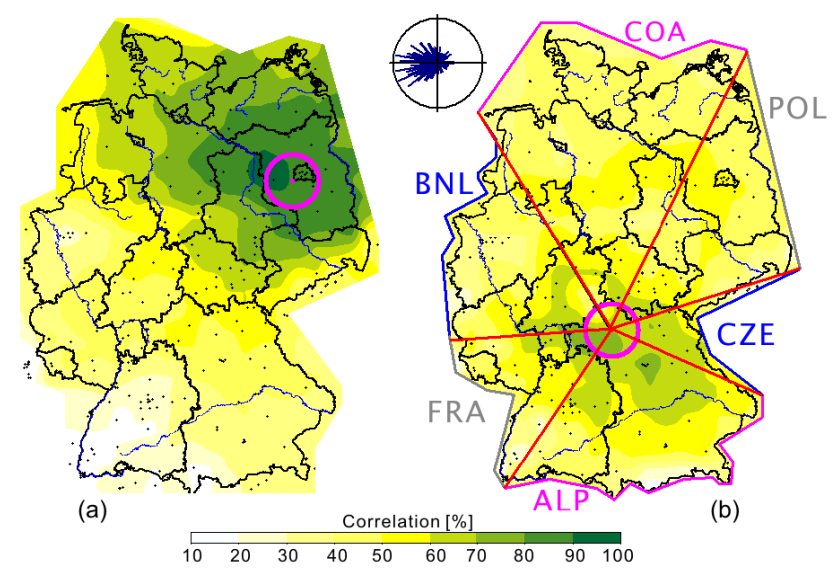

Figure 1. (a) Example for a map with correlation isolines. Shown are the correlations with the station Potsdam (magenta dot). The magenta ring around the station is the so-called influence circle which is needed to determine the magnitude of the large-scale $\mathrm{PM}_{10}$ background. (b) Example of a correlation map for the wintertime $\mathrm{PM}_{10}$ concentration residuals $\left(\mathrm{I}_{\mathrm{B}}+\mathrm{I}_{\mathrm{S}}\right)$ at station Schweinfurt (see also Sect. 4.4). Shown are the six segments of the German border along which the large-scale background is computed: Coastal (COA), Poland (POL), Czech Republic (CZE), alpine (ALP), France (FRA) and Belgium/Netherlands/Luxemburg (BNL). The polar plot in the top left corner indicates the frequency distribution of the surface wind direction for the southern half of Germany (south of $50^{\circ} \mathrm{N}$ ).

gression selects most frequently are the thermal wind of the $850 / 1000 \mathrm{hPa}$ layer, the geopotential gradient of the $500 \mathrm{hPa}$ level and the temperature gradient in $850 \mathrm{hPa}$.

\subsection{Determination of the large-scale background and the stochastic portion}

Having quantified and removed the local $\mathrm{PM}_{10}$ portion leaves the combination of $\mathrm{I}_{\mathrm{S}}+\mathrm{I}_{\mathrm{B}}$, the residual concentration, to be analyzed further. For a given station $\mathrm{X}$, the correlations of the $\mathrm{PM}_{10}$-series (having $\mathrm{I}_{\mathrm{L}}$ removed) with all others is computed. This results in a geographical distribution of correlations which is visualized as a map with colour-coded isocorrelates, as shown in Fig. 1a. The correlations are computed using a set of stations within and without Germany (cf. Sect. 2) of which only those in Germany or in close proximity to the border are graphed in the maps of this paper.

In order to derive the large-scale background, a qualitative and a quantitative argument is used. Let us begin with the qualitative reasoning. If we assume that the association between the time series at the reference station and all others were perfect, then the correlation coefficient would be equal to 1, i.e., the map displayed in Fig. 1a were entirely in dark green colour and there would be no stochastic component. Thus, whatever deviation from a correlation coefficient of 1 exists indicates the magnitude of the stochastic component 


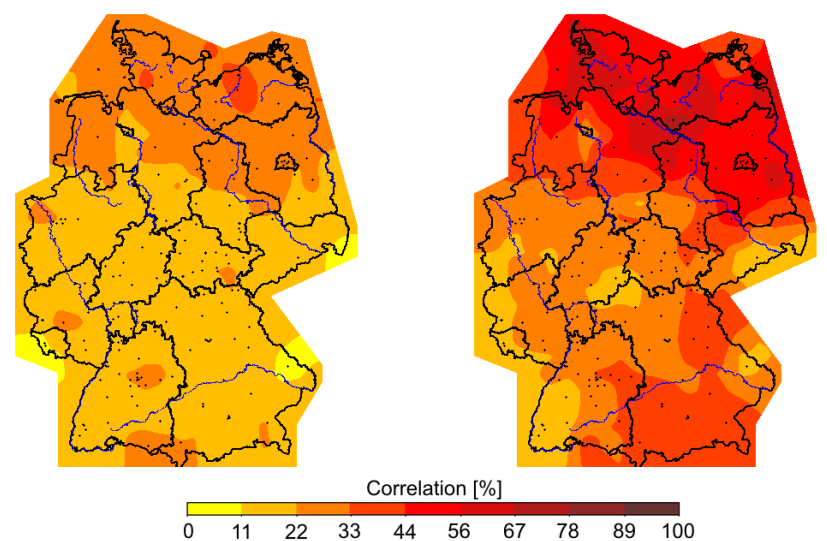

Figure 2. Large-scale background portion (in per cent) of $\mathrm{PM}_{10}$ concentrations derived by evaluating the correlation between each time series with every other series. Left: Summer, right: winter conditions.

Is. This component includes, regardless of the small or large scale character of the signal (i) the asynchronous behaviour of the time series involved, (ii) $\mathrm{PM}_{10}$ transformations, (iii) $\mathrm{PM}_{10}$ sources and sinks and (iv) $\mathrm{PM}_{10}$ mixing.

Let us now turn to the quantitative reasoning. It involves the definition of a so-called influence circle around the reference station which is indicated as a magenta ring in Fig. 1a. It is assumed that whatever remaining local influence there might be tapers off at a distance of $50 \mathrm{~km}$ from the reference station. The size of the circle is empirically determined as a balance between the minimization of local influences and retaining as much as possible of the large-scale background ${ }^{1}$. In the iso-correlation map, the squared correlation is averaged along this influence circle. This is necessary because the explained co-variance between measurement series is assessed. It should be pointed out that this procedure evaluates the correlation in the neighbourhood of the station outside the influence circle but ignores all correlation values from its immediate vicinity, i.e., from within the circle.

Therefore, the stochastic portion vanishes if the correlation coefficient along the influence circle equals 1 ; the large-scale background vanishes if the the correlations coefficient equals 0 ; the local portion vanishes if the mean total concentration at a station equals the standard deviation of the station's series. The latter indeed happens but such cases are (i) extremely rare in the analyzed data set and (ii) indicate that the station is representative only for a very confined area because its $\mathrm{PM}_{10^{-}}$ variability is extremely deviating from that in the surrounding area (example: a single, highly traffic-influenced station

\footnotetext{
${ }^{1}$ Tests with different sizes of the circle showed that too small diameters would for some stations place too few reference points (i.e. other measuring stations) in its vicinity; enlarging the circle, on the other hand leads to an increasing stochastic portion and an artificial reduction of the target property: the large-scale background.
}

in a rural part of the network); Flemming et al. (2005) analyzed the spatial representativeness of different station types and developed a revised objective classification scheme for air quality regimes.

\subsection{Example for the component separation}

Here is an example using concentration data from a $\mathrm{PM}_{10}$ station (Potsdam), taken between 2001 and 2003; the winter half-year is selected. A total average daily concentration $\mathrm{T}_{\mathrm{C}}$ of $29.2 \mu \mathrm{g} / \mathrm{m}^{3}(=100 \%)$ occurred with a standard deviation Sdev of $19.3 \mu \mathrm{g} / \mathrm{m}^{3}$. The averaged (squared) correlation over the $50 \mathrm{~km}$ influence circle yielded a value of $R=0.79$.

- Stochastic portion IS:

$(1-R) \cdot \operatorname{Sdev}=4.1 \mu \mathrm{g} / \mathrm{m}^{3}$ or as a percentage

$4.1 / \mathrm{T}_{\mathrm{C}} \cdot 100=14 \%$.

- Large-scale background $\mathrm{I}_{\mathrm{B}}$ :

$R \cdot \operatorname{Sdev}=15.2 \mu \mathrm{g} / \mathrm{m}^{3}$ or as a percentage

$15.2 / \mathrm{T}_{\mathrm{C}} \cdot 100=52 \%$.

- Local portion $\mathrm{I}_{\mathrm{L}}$ :

$\mathrm{T}_{\mathrm{C}}\left(\mathrm{I}_{\mathrm{S}}+\mathrm{I}_{\mathrm{B}}\right)=9.9 \mu \mathrm{g} / \mathrm{m}^{3}$ or as a percentage

$9.9 / \mathrm{T}_{\mathrm{C}} \cdot 100=34 \%$.

\section{Results}

\subsection{Signal strength assessment}

An important first step is the assessment of the overall potential of detecting signals by way of correlation analysis. Figure 2 shows that correlation is not only indicative of the $\mathrm{PM}_{10}$ large-scale background magnitude but can be used as well to determine in which regions strong signals can be expected at all. This is achieved by computing the correlation of all stations with all others (not, as in the other maps, of one station with all others) and extracting the long range transport portions as described in Sect. 3.4. The respective percentages for the average summer and winter conditions from the period 2001-2003 are graphed in Fig. 2.

The extended areas with a large-scale background portion of about $30 \%$ in summer and of $50 \%$ or more in winter indicate a good detectability of signals in the north half of Germany and, at least in the wintertime, in southern and eastern Bavaria, too. The seasonal difference in magnitude can be explained by a stronger atmospheric motion in winter which results in stronger transports.

Kreienkamp et al. (2007) give tables of $\mathrm{I}_{\mathrm{B}}, \mathrm{I}_{\mathrm{L}}, \mathrm{I}_{\mathrm{S}}$ and $\mathrm{T}_{\mathrm{C}}$ using STAT-IMM for a selection of German stations which aims at a good geographic coverage. $I_{B}$ tends to be in a range of $25-50 \%$; the same range was found for these stations where $\mathrm{I}_{\mathrm{L}}$ and $\mathrm{I}_{\mathrm{S}}$ amount to $20-40 \%$. 
Table 1. Breakdown of the total $\mathrm{PM}_{10}$ concentration $\left(\mathrm{T}_{\mathrm{C}}\right)$ into the large-scale background $\left(\mathrm{I}_{\mathrm{B}}\right)$, the local portion ( $\left.\mathrm{I}_{\mathrm{L}}\right)$ and the stochastic portion $\left(\mathrm{I}_{\mathrm{S}}\right)$ at station Braunschweig for 2001-2003 wintertime data. The three portions are displayed in terms of percentage and amount $\left[\mu \mathrm{g} / \mathrm{m}^{3}\right]$. The columns indicate if all winter days (all) or the classes very low (vlow), low, medium (med), high (hi) or very high (vhi) were used. The number of days in each class is given in parantheses. The tabulated information corresponds with the maps in Fig. 3.

\begin{tabular}{|c|c|c|c|c|c|c|c|c|c|c|c|c|}
\hline & \multicolumn{2}{|c|}{ all (546) } & \multicolumn{2}{|c|}{ vlow (171) } & \multicolumn{2}{|c|}{ low (117) } & \multicolumn{2}{|c|}{ med (81) } & \multicolumn{2}{|c|}{ high (99) } & \multicolumn{2}{|c|}{ vhi (78) } \\
\hline & $\%$ & $\mu \mathrm{g} / \mathrm{m}^{3}$ & $\%$ & $\mu \mathrm{g} / \mathrm{m}^{3}$ & $\%$ & $\mu \mathrm{g} / \mathrm{m}^{3}$ & $\%$ & $\mu \mathrm{g} / \mathrm{m}^{3}$ & $\%$ & $\mu \mathrm{g} / \mathrm{m}^{3}$ & $\%$ & $\mu \mathrm{g} / \mathrm{m}^{3}$ \\
\hline $\mathrm{T}_{\mathrm{C}}$ & & 45.2 & & 30.8 & & 43.8 & & 46.6 & & 51.1 & & 70.0 \\
\hline $\mathrm{I}_{\mathrm{B}}$ & 27 & 12.0 & 16 & 5.0 & 14 & 6.1 & 14 & 6.4 & 17 & 8.9 & 30 & 21.3 \\
\hline $\mathrm{I}_{\mathrm{L}}$ & 47 & 21.2 & 61 & 18.9 & 62 & 27.0 & 62 & 28.9 & 57 & 29.1 & 49 & 34.5 \\
\hline $\mathrm{I}_{\mathrm{S}}$ & 26 & 12.0 & 22 & 6.9 & 24 & 10.7 & 24 & 11.3 & 25 & 13.0 & 20 & 14.3 \\
\hline
\end{tabular}

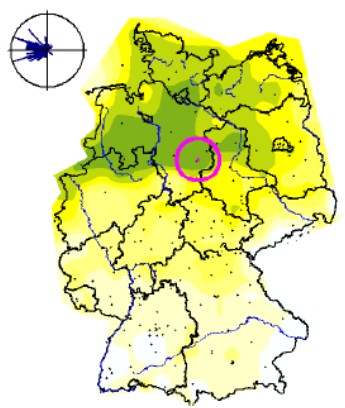

(a) vlow

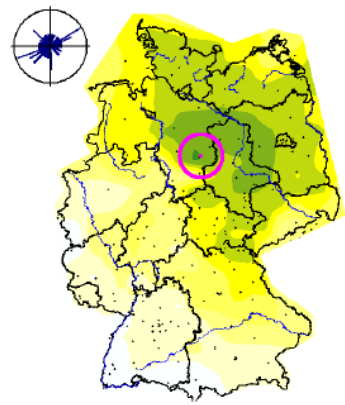

(d) hi

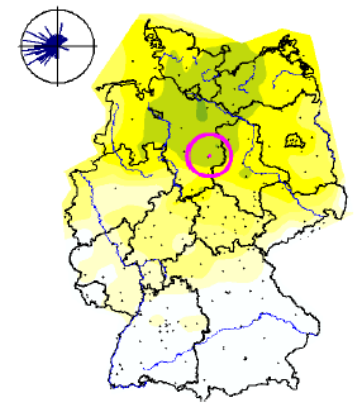

(b) low

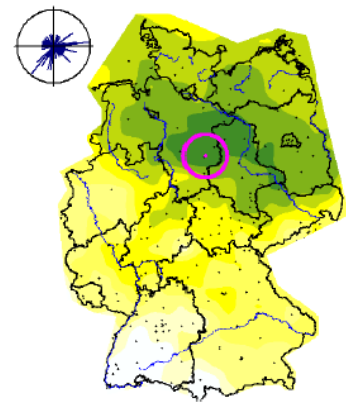

(e) vhi

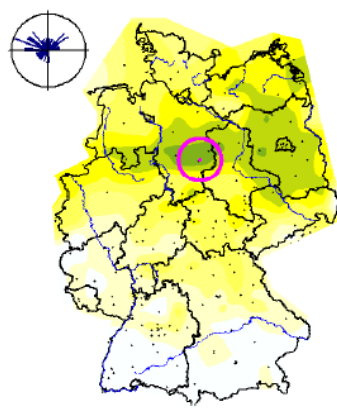

(c) med

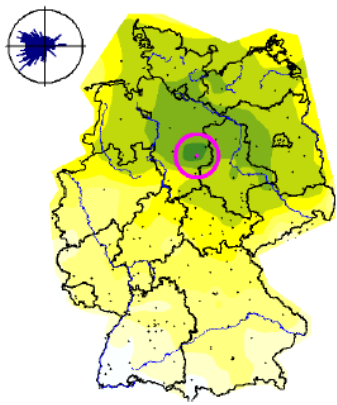

(f) all

Correlation [\%]

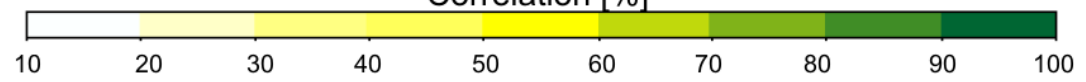

Figure 3. Map of the correlation of the residual (large-scale background plus stochastic portion) $\mathrm{PM}_{10}$ time series at Station Braunschweig with all other stations. The subfigures display the concentration magnitudes: (a) very low; (b) low; (c) medium; (d) high; (e) very high and (f) all days, i.e., without magnitude differentiation. The three portions of the total concentration for each class are given in Table 1.

\subsection{Dependence on concentration levels}

For the following analyses we have picked the station Braunschweig, because it is located in the area with a strong overall signal (see Fig. 2 and Sect. 4.1) and it is closer to the geometric center of Germany, thus enabling a more uniform picture, e.g., with respect to advection. Figure 3 shows the correlation maps for wintertime $\mathrm{PM}_{10}$ levels at this station, stratified by five classes and Table 1 shows the three concentration portions for the five classes.
In the top left corner of each subfigure a wind direction polar plot indicates the frequency distribution of the wind direction for the respective class. This $\mathrm{PM}_{10}$ concentration/wind direction-relation can be assessed from Fig. 3 and Table 1, keeping in mind that the property analyzed to obtain Fig. 3 is the $\mathrm{PM}_{10}$ residuum, i.e., after the removal of the local portion $\mathrm{I}_{\mathrm{L}}$. Thus a combination of large-scale background and stochastical portion is retained. It should be added that the classification for the concentration magnitude 
Table 2. Cross-boundary analysis of large-scale background $\mathrm{PM}_{10}$ concentrations for station Potsdam stratified by wind direction (columns). Tabulated is the Total Concentration $\left(\mathrm{T}_{\mathrm{C}}\right)$, and, as percentage and in $\mu \mathrm{g} / \mathrm{m}^{3}$, the large-scale background $\left(\mathrm{I}_{\mathrm{B}}\right)$ and the portion (of $\mathrm{T}_{\mathrm{C}}$ ) of the cross-boundary transport for the coastal (COA) and the Polish (POL) segment. Wintertime data from 2001-2003 have been used.

\begin{tabular}{lrrrrrrrr}
\hline & \multicolumn{2}{c}{ Northeast } & \multicolumn{2}{c}{ Northwest } & \multicolumn{2}{c}{ Southwest } & \multicolumn{2}{c}{ Southeast } \\
& $\%$ & $\mu \mathrm{g} / \mathrm{m}^{3}$ & $\%$ & $\mu \mathrm{g} / \mathrm{m}^{3}$ & $\%$ & $\mu \mathrm{g} / \mathrm{m}^{3}$ & $\%$ & $\mu \mathrm{g} / \mathrm{m}^{3}$ \\
\hline $\mathrm{T}_{\mathrm{C}}$ & & 29.2 & & 24.5 & & 29.4 & & 52.1 \\
$\mathrm{I}_{\mathrm{B}}$ & 45 & 13.2 & 56 & 13.6 & 41 & 12.2 & 36 & 19.6 \\
$\mathrm{POL}$ & 11 & 3.2 & 13 & 3.2 & 9 & 2.5 & 8 & 4.2 \\
$\mathrm{COA}$ & 4 & 1.2 & 7 & 1.7 & 4 & 1.0 & - & - \\
\hline
\end{tabular}

is not station-based but groups days with the respective levels averaged over the whole northwest corner (north of $50 \mathrm{~N}$ and west of 12E) of Germany.

- The (removed) local portion clearly dominates the time series with values around $50 \%$ and more.

- Even at a low residuum concentrations there are high correlations; in this value range the correlations tend to be strongly associated with the wind direction.

- With higher concentration levels the wind directions tends to be a factor of decreasing importance for the shape of the strong correlation maximum surrounding the station; yet, if there were no direction-dependence, this maximum would be perfectly circular.

- Whereas the local portion and the stochastic portion do not vary much there is almost a doubling of the large-scale background towards the highest concentration class. This behaviour is in conjunction with the wind direction-dependency of $\mathrm{PM}_{10}$ concentrations (cf. Sect. 4.3) and can, at least in part, be explained by an above-average share of southeasterly winds for days with peak $\mathrm{PM}_{10}$ concentrations.

\subsection{Dependence on wind direction}

When stratifying the data according to wind direction, problems arise because of the uneven distribution in the four quadrants which disallows a further differentiation, e.g., according to magnitude classes. The unevenness can already be deduced from the wind direction polar plot in Fig. 3 where the NW and SW sector are much more frequent than the $\mathrm{NE}$ and SE sectors. It turns out that southeasterly winds, i.e., in the most infrequent quadrant (less than $10 \%$ of all days) nevertheless are associated with the highest correlations. Yet, the shape of the correlation maximum is oriented away from and perpendicular to the SE quadrant. This underlines that wind direction and $\mathrm{PM}_{10}$ concentrations are exhibiting a more complex linkage than one might be tempted to assume. Owing to the concept behind correlations, it also indicates that synchronous behaviour in $\mathrm{PM}_{10}$ time series exists downwind, which points at the area of the station as a source of $\mathrm{PM}_{10}$ variability. Consequently, the shape of the correlation maximum in the maps must be interpreted with caution.

\subsection{Large-scale background and cross-border $\mathrm{PM}_{10}$ transport}

In principle, the correlation-based analysis of $\mathrm{PM}_{10}$ concentrations is not restricted to an evaluation along the $50 \mathrm{~km}$ circle around the reference station. It was, indeed, carried out along stretches of the boundary, too, as shown in Fig. $1 \mathrm{~b}$. The example of station Schweinfurt is used because it has significant (the $95 \%$ significance level for correlations based on 500 values is, e.g., 0.09) cross-border large-scale background amounts for all border segments. In other areas of Germany, these amounts were significant only for a few segments. Stations in proximity to boundaries show that up to half of $I_{B}$ is linked to that boundary, but this behaviour tapers off with distance. This entire effect is best developed in Northern Germany where the overall signal magnitude is largest (cf. Sect. 4.1 and Fig. 2). In conjunction with the Alps or the French border, no strong large-scale background signals are detected.

A note of caution: Correlations, by themselves, cannot be used to conclude if transports take place from or towards an area. This is a consequence of the facts discussed in Sects. 4.2 and 4.3. However, in principle, it is possible to combine correlation results with a directional analysis, e.g., by examining them in conjunction with wind direction information. The limitations caused by the imperfect concentration/wind direction-linkage notwithstanding, an attempt was made to analyze the cross-border data stratified by wind direction and an example result is given in Table 2 .

When comparing the tabulated values with the information from Fig. 2 it becomes clear that only the coastal and the Polish boundary segment bear potential for cross-boundary transports, due to the shape of the correlation maximum. There is a pronounced direction-dependency which can be seen, e.g., in the presence of the strongest coastal influence for the NW wind quadrant as well as in the absence of a coastal portion for the SE wind quadrant. The linkage to cross-boundary transport w.r.t. Poland is visible best when 
looking at the concentration levels in $\mu \mathrm{g} / \mathrm{m}^{3}$ where the SE quadrant exhibits the highest values. However, due to the relative proximity of the station to the Polish border, significant values are found for all wind directions.

\section{Conclusions}

\subsection{General remarks and comparison with other studies}

The statistical method STAT-IMM, which analyzes $\mathrm{PM}_{10}$ concentrations rather then $\mathrm{PM}_{10}$ emissions, has shown to be a workable approach to separate and quantify the three shares in $\mathrm{PM}_{10}$ measurement series: Local portion, largescale background and stochastic portion. These are are contained jointly in the $\mathrm{PM}_{10}$ series. We do not claim that STATIMM yields a perfect separation - for example the local portion (expressed by the weather influence) can only be minimized and not fully excluded. However, the approach with its combination of regression and correlation constitutes an alternative to the established methods (see Sects. 1.2 and 5.1 ), relying neither on chemical nor on purely physical modelling.

There are but very few comprehensive studies in which the three $\mathrm{PM}_{10}$ portions were determined for all of Germany. In Diegmann et al. (2006) (referred to as DEA06 hereafter) there is a compilation of $I_{S}, I_{B}$ and $I_{L}$ for 37 Stations. They are neither covering all of the country, nor was the DEA06 analysis carried out using a common timeframe. However, a key finding was that $\mathrm{I}_{\mathrm{B}}$ tends to be present in all series with a fraction of at least $30 \%$ and at most $70 \%$. Another finding was that for 34 out of these 37 stations $I_{B}$ is the strongest contributor - rivalled for a subset of 10 stations by a traffic-related local contribution of comparable magnitude. $\mathrm{I}_{\mathrm{L}}$, termed "urban load" in DEA06 ranges from virtual nonexistence to a fraction of over $40 \%$, which is also the case for $\mathrm{I}_{\mathrm{S}}$, termed "additional load" in DEA06. The corresponding STAT-IMM results have been shown at the end of Sect. 4.1. Because the time frame and the detection regions of DEA06 and this study are not congruent, a full match of the magnitudes of the results can not be expected - in fact, taking the large-scale background as an example, STAT-IMM predominantly indicates lower portions.

An other study to compare some of the STAT-IMM results with is the Stern (2006) report (referred to as S06 hereafter). Its subject is the modelling - using the REM-CALGRID model - of cross-boundary transports of $\mathrm{PM}_{10}$ and $\mathrm{NO}_{2}$. S06 focuses on the concentrations that arrive from sources in Poland at twelve $\mathrm{PM}_{10}$ stations in Berlin; its time frame is the year 2002. They were computed to be around $10 \%$ of the total $\mathrm{PM}_{10}$ concentrations. This magnitude is matched by the STAT-IMM findings, although we used a longer time frame.

\subsection{Evaluation}

One topic that needs to be addressed is the robustness of the STAT-IMM results. Due to the short time span for which $\mathrm{PM}_{10}$ data were available a cross validation which would have developed the statistical relations on a sub-period and applied them to the complementary sub-period was not possible. Yet precautions were taken with respect to the statistic stability. These include the log-transformation of the initial values to ensure a better approximation to Gaussian probability density functions as well as a limitation to a selection of up to four predictors in the screening regression.

Could the discrimination abilities of STAT-IMM with respect to the three $\mathrm{PM}_{10}$ shares be enhanced if all potential predictors were to be used to determine the local portion? It would appear that in this case the weather factors were more fully taken into account. But, as explained in Sect. 3.2, using such an approach would blur the distinctions between local and large-scale weather influences and thus have a detrimental effect on the determination of the large-scale background.

However, there seems to be a potential "correlation sink" in the amount assigned to the stochastical portion, where some information might be buried due to the fact that correlations evaluate synchronous behaviour in the time series. Using lag correlations is not helpful since they are employing a fixed lag and whatever lagged behaviour might exist would be different for each station due to the varying distances. This effect would assign too much of the correlation to the stochastic side, thus overestimating the stochastic portion. Nevertheless, when prudently interpreting the statistical analyses it can be stated that, particularly for the large-scale background, there is a dependence on magnitude as well as on advection.

Acknowledgements. This project was funded by the German Federal Environment Agency (UBA) under grant 20543223. Fruitful discussion with the late R. Lacombe furthered the initial stages of its development. Thorough comments by the former UBA department head W.-D. Garber greatly helped in the writing process of the grant's report which paved the way for this paper. We are furthermore grateful for support and critical notes by UBA scientists B. Kahra and A. Graff as well as we acknowledge the insightful comments of two reviewers.

Edited by: A. Baklanov

Reviewed by: two anonymous referees

\section{References}

Danielsen, E. F.: Review of Trajectory Methods, Adv. Geophys., 18B, 73-94, 1974.

Diegmann, V., Pfäfflin, F., Wiegand, and Wursthorn: Maßnahmen zur Reduzierung von Feinstaub und Stickstoffdioxid, Endbericht, Grant 20442 222, German Federal Environment Agency (UBA), 2006. 
Enke, W. and Spekat, A.: Downscaling Climate Model Outputs into local and regional Weather Elements by Classification and Regression, Clim. Res., 8, 195-207, 1997.

EU: Council Directive 96/62/EC of September 27 on Ambient Air Quality Assessment and Management, Official Journal of the European Communities, L296/55, published: 21 November 1996.

EU: Council Decision of 27 January 1997 Establishing a Reciprocal Exchange of Information and Data from Networks and Individual Stations Measuring Ambient Air Pollution Within the Member States (97/101/EC), Official Journal of the European Commission, L035, 0014-0022, published: 5 February 1997.

EU: Council Directive 1999/30/EC of 22 April 1999 Relating to Limit Values for Sulphur Dioxide, Nitrogen Dioxide and Oxides of Nitrogen, Particulate Matter and Lead in Ambient Air, Official Journal of the European Commission, L163/41, published: 29 June 1999.

Flemming, J., Stern, R., and Yamartino, R. J.: A new air quality regime classification scheme for $\mathrm{O}_{3}, \mathrm{NO}_{2}, \mathrm{SO}_{2}$ and $\mathrm{PM}_{10}$ observation sites, Atmos. Environ., 39, 6121-6129, 2005.

Garber, W., Colosio, J., Grittner, S., Larssen, S., Rasse, D., Schneider, J., and Houssiau, M.: Guidance to the Annexes to Decision 97/101/EC on Exchange of Information as revised by Decision 2001/752/EC, for the European Commission, DG Environment, 2002.

Hainisch, A. and Neubauer, S.: Feinstaubimmissionen in Mecklenburg-Vorpommern, Materialien zur Umwelt, Schwerin, Mecklenburg-Vorpommern, Landesamt für Umwelt, Naturschutz und Geologie, 2004.

Harris, J. M. and Kahl, J. D.: A Descriptive Atmospheric Transport Climatology for the Mauna Loa Oberservatory, using Clustered Trajectories, J. Geophys. Res., 95, 13 651-13 667, 1990.

Kalnay, E., Kanamitsu, M., Kistler, R., Collins, W., Deaven, D., Gandin, L., Iredell, M., Saha, S., Whitea, G., Woolen, J., Zhu, Y., Chelliah, M., Ebisuzaki, W., Higgins, W., Janowiak, J., Mo, K., Ropelewski, C., Wang, J., Leetmaa, A., Reynolds, R., Jenne, R., and Joseph, D.: The NCEP/NCAR 40-year Reanalysis Project, B. Am. Meteorol. Soc., 77, 437-471, 1996.

Klein, W. H.: Computer predictions of precipitation probability in the United States, J. Appl. Meteorol., 10, 903-915, 1971.

Kreienkamp, F. and Enke, W.: Nationale Luftreinhaltestrategie Umsetzung von EU-Anforderungen. Teilprojekt 1: Entwicklung operationeller automatischer Verfahren zur Validierung von Immisionsmesswerten als Teil eines Qualitätssicherungssystems, Schlussbericht, FKZ 20343 257/01, Bundesministerium für Umwelt, Naturschutz und Reaktorsicherheit, 2005.

Kreienkamp, F., Enke, W., and Spekat, A.: Untersuchung des Einflusses des Wetters auf die Feinstaubbelastung in Deutschland, Abschlussbericht, Grant 20543 223, German Federal Environment Angency (UBA), 2007.

Kruizinga, S. and Murphy, A. H.: Use of an analogue procedure to formulate objective probabilistic temperature forecasts in the Netherlands, Mon. Weather Rev., 111, 2244-2254, 1989.

Lenschow, P., Abraham, H.-J., Kutzner, K., Lutz, M., Preuß, J.-D., and Reichenbächer, W.: Some Ideas about the Sources of $\mathrm{PM}_{10}$, Atmos. Environ., 35 Suppl. 1, S23-S33, 2001.

Man, C. K. and Shih, M. Y.: Identification of sources of $\mathrm{PM}_{10}$ aerosols in Hong Kong by wind trajectory analysis, J. Aerosol Sci., 32, 1213-1223, 2001.
Merrill, J. T., Bleck, R., and Avila, L.: Modeling Armospheric Transport to the Marshal Islands, J. Geophys. Res., 90(D7), 12927-12 936, 1985.

Oltmans, S. J., Levy II, H., Harris, J. M., Merrill, J. T., Moody, J. L., Lathrap, J. A., Cuevas, E., Trainer, M., O’Neill, M. S., Prospero, J. M., Vömel, H., and Johnson, B. J.: Summer and Spring Ozone Profiles over the North Atlantic from Ozonesonde Measurements, J. Geophys. Res., 101(D22), 29 179-29 200, 1996.

Querol, X., Alastuey, A., Ruiz, C. R., Artiñano, B., Hansson, H. C., Harrison, R. M., Buringh, E., Ten Brink, H. M., Lutz, M., Bruckmann, P., Staehl, P., and Schneider, J.: Speciation and Origin of $\mathrm{PM}_{10}$ and $\mathrm{PM}_{2.5}$ in Selected European Cities, Atmos. Environ., 38, 6547-6555, 2004.

Querol, X., Viana, M., Alastuey, A., Amato, F., Moreno, T., Castillo, S., Pey, J., de la Rosa, J., Sánchez de la Campa, A., Artiñano, B., Salvador, P., Garcia Dos Dantos, S., FernándezPatier, R., Moreno-Grau, S., Negrai, L., Minguillón, M. C., Monfort, E., Gif, J. L., Inza, A., Ortega, L. A., Santamaria, J. M., and Zabalza, J.: Source Origins of Trace Elements in PM from Regional Background, Urban and Industrial Sites of Spain, Atmos. Environ., 41, 7219-7231, 2007.

Seibert, P.: Convergence and Accuracy of Numerical Methods for Trajectory Calculations, J. Appl. Meteorol., 32, 558-566, 1993.

Stern, R.: Entwicklung und Anwendung des chemischen Transportmodells REM/CALGRID. Abschlussbericht zum Forschungsund Entwicklungsverfahrens: Modellierung und Prüfung von Strategien zur Verminderung der Belastung durch Ozon, Grant 29841 252, German Federal Environment Angency (UBA), 2003.

Stern, R.: Der Beitrag des Ferntransports zu den $\mathrm{PM}_{10^{-}}$und den $\mathrm{NO}_{2}$-Konzentrationen in Deutschland unter besonderer Betrachtung der polnischen Emissionen: Eine Modellstudie, Freie Universität Berlin, Institut für Meteorologie, Troposphärische Umweltforschung, 2006.

Stohl, A. and Kromp-Kolb, H.: Origin Of Ozone In Vienna And Surroundings, Austria, Atmos. Environ., 28, 1255-1266, 1994.

van Dingenen, R., Raes, F., Putaud, J.-P., Baltensperger, U., Charron, A., Facchini, M.-C., Descari, S., Fuzzi, S., Gehrig, R., Hansson, H. C., Harrison, R. M., Hüglin, C., Jones, A. M., Laj, P., Lorbeer, G., Maenhaut, W., Palmgren, F., Querol, X., Rodriguez, S., Schneider, J., ten Brink, H., Tunved, P., Tørseth, K., Wehner, B., Weingartner, E., Wiedensohler, A., and Wåhlin, P.: A European Aerosol Phenomenology - 1: Physical Characteristics of Particulate Matter at Kerbside, Urban, Rural and Background Sites in Europe, Atmos. Environ., 38, 2561-2577, 2004.

van Loon, M., Roemer, M., and Builtjes, P.: Model intercomparison in the framework of the review of the Unified EMEP, TNO Report R 2004/282, Delft, The Netherlands, 2004.

Warnecke, C., Wouters, F., Kuhlbusch, Th., Hugo, A., Rating, U., and Koch, M.: $\mathrm{PM}_{10}$ Quellgruppenanalyse als Teilvorhaben TV4 der Analyse der Immissionsbelastung in Deutschland durch Ferntransporte (Final Report), Grant 20442 202/04, German Federal Environment Agency (UBA), 2006.

Yamartino, R. J., Scire, J. S., Carmichael, G. R., and Chang, Y. S.: The CALGRID Mesoscale Photochemical Model - I: Model Formulation, Atmos. Environ., 26A, 1493-1512, 1992. 